\title{
Two New Algorithms for Discrete Boundary Value Problems*
}

\author{
Ravi P. Agarwal and Tara R. Nanda \\ Department of Mathematics \\ National University of Singapore \\ 10 Kent Ridge Crescent, Singapore 0511.
}

\begin{abstract}
We propose two new methods of constructing the solutions of linear multi-point discrete boundary value problems. These methods are applied to solve some continuous two-point boundary value problems which are known to be numerically unstable.

Key words: Adjoint Identities, Discrete Systems, Multi-point Boundary Value Problems.
\end{abstract}

AMS Subject Classification: 65Q05, 65L10.

\section{INTRODUCTION}

The purpose of this paper is to provide two new algorithms to compute the solution of the linear discrete system

$$
\mathrm{u}(\mathrm{k}+1)=\mathrm{A}(\mathrm{k}) \mathrm{u}(\mathrm{k})+\mathrm{b}(\mathrm{k}), \mathrm{k} \in \mathrm{N}\left(\mathrm{k}_{1}, \mathrm{k}_{\mathrm{r}}\right)
$$

satisfying the multi-point boundary conditions

$$
\sum_{i=1}^{r} \sum_{p=1}^{n} \alpha_{q p}^{i} u_{p}\left(k_{i}\right)=l_{q}, 1 \leq q \leq n
$$

where $\mathrm{A}(\mathrm{k})$ is a given nonsingular $\mathrm{n} \times \mathrm{n}$ matrix with elements $\mathrm{a}_{\mathrm{qp}}(\mathrm{k}), 1 \leq \mathrm{q}, \mathrm{p} \leq \mathrm{n} ; \mathrm{b}(\mathrm{k})$ is a given $n \times 1$ vector with components $b_{q}(k), 1 \leq q \leq n ; u(k)$ is an unknown $n x 1$ vector with components $\mathrm{u}_{\mathrm{q}}(\mathrm{k}), 1 \leq \mathrm{q} \leq \mathrm{n} ; 0 \leq \mathrm{k}_{1}<\mathrm{k}_{2}<\ldots<\mathrm{k}_{\mathrm{r}}(\mathrm{r} \geq 2)$ where each $\mathrm{k}_{\mathrm{i}}$ is a positive integer, $\mathrm{N}\left(\mathrm{k}_{1}, \mathrm{k}_{\mathrm{r}}\right)$ is the discrete interval $\left[\mathrm{k}_{1}, \mathrm{k}_{1}+1, \ldots, \mathrm{k}_{\mathrm{r}}\right] ; \alpha_{\mathrm{qp}}^{\mathrm{i}}, \mathrm{l}_{\mathrm{q}}, 1 \leq \mathrm{q}, \mathrm{p} \leq \mathrm{n}$, $1 \leq \mathrm{i} \leq \mathrm{r}$ are given constants.

In particular we shall also consider the system (1.1) together with the implicit separated boundary conditions

$$
\sum_{p=1}^{n} \alpha_{i\left(s_{i}\right), p} u_{p}\left(k_{i}\right)=t_{i, i}\left(s_{i}\right) ; 1 \leq i \leq r \leq(2 \leq r \leq n),
$$

where $s_{1}=1,2, \ldots, \beta_{1} ; \ldots ; s_{r}=1,2, \ldots, \beta_{r}$ and $\sum_{i=1}^{r} \beta_{i}=n$. The subscript $i\left(s_{i}\right)$ allows the possibility that at the same point $k_{i}$ several boundary conditions are prescribed.

*Received: September 1989; Revised: December 1989. 
Motivated by the work of Angel and Kalaba [4] on two-point boundary value problems for difference equations, recently in $[1,3,7,12]$, we have discussed several new methods of constructing the solutions of linear as well as nonlinear multi-point discrete boundary value problems. In this paper we shall develop adjoint identities which are in terms of solutions of (1.1) and its adjoint system. These identities lead to the backwardforward and forward-backward methods, which seem to be new processes for computing the solutions of (1.1) and (1.2). However, the application of adjoint equations to solve discrete problems is not new, e.g., Clenshaw [6] used adjoint difference equations to sum the Chebyshev series. To demonstrate the usefulness of the proposed methods we solve some continuous two-point boundary value problems which are known to be unstable.

\section{BACKWARD-FORWARD AND FORWARD-BACKWARD METHODS}

The adjoint system of the difference system (1.1) is defined as

$$
v(k)=A^{T}(k) v(k+1), k \in N\left(k_{1}, k_{r}\right)
$$

where $A^{T}(k)$ is an $n \times n$ matrix with elements $a_{q p}(k), 1 \leq p, q \leq n$ and $v(k)$ is an $n \times 1$ vector with components $\mathrm{v}_{\mathrm{q}}(\mathrm{k}), 1 \leq \mathrm{q} \leq \mathrm{n}$. obtain

We multiply the qth equation of $(1.1)$ by $\mathrm{v}_{\mathrm{q}}(\mathrm{k}+1)$ and sum over all $\mathrm{n}$ equations to

$$
\sum_{q=1}^{n} u_{q}(k+1) v_{q}(k+1)=\sum_{q=1}^{n} v_{q}(k+1) \sum_{p=1}^{n} a_{q p}(k) u_{p}(k)+\sum_{q=1}^{n} b_{q}(k) v_{q}(k+1) .
$$

Next we multiply the qth equation of $(2.1)$ by $u_{q}(k)$ and sum over all $n$ equations to get

$$
\sum_{q=1}^{n} u_{q}(k) v_{q}(k)=\sum_{q=1}^{n} u_{q}(k) \sum_{p=1}^{n} a_{q p}(k) v_{p}(k+1)
$$

On subtracting (2.3) from (2.2), we find

$$
\sum_{q=1}^{n}\left[u_{q}(k+1) v_{q}(k+1)-u_{q}(k) v_{q}(k)\right]=\sum_{q=1}^{n} b_{q}(k) v_{q}(k+1) .
$$

Let $k_{0} \in N\left(k_{1}, k_{r}\right)$ be fixed. In (2.4) letting $k=l$ and summing from $k_{0}$ to $k-1 \in N\left(k_{1}, k_{r}\right)$ results in

$$
\begin{gathered}
\sum_{q=1}^{n}\left[u_{q}(k) v_{q}(k)-u_{q}\left(k_{0}\right) v_{q}\left(k_{0}\right)\right]=\sum_{l=k_{0}+1}^{k} \sum_{q=1}^{n} v_{q}(l) b_{q}(l-1), \\
\text { for all } k_{0} \leq k \in N\left(k_{1}, k_{r}\right)
\end{gathered}
$$


and, similarly

$$
\begin{gathered}
\sum_{q=1}^{n}\left[u_{q}(k) v_{q}(k)-u_{q}\left(k_{0}\right) v_{q}\left(k_{0}\right)\right]=-\sum_{l=k+1}^{k_{0}} \sum_{q=1}^{n} v_{q}(l) b_{q}(l-1), \\
\text { for all } k_{0} \geq k \in N\left(k_{1}, k_{r}\right) .
\end{gathered}
$$

Equations (2.5) and (2.6) will be referred to as adjoint identities. We compute backward solutions once for each $\mathrm{u}_{\mathrm{q}}\left(\mathrm{k}_{\mathrm{i}}\right), 2 \leq \mathrm{i} \leq \mathrm{r}$ appearing in (1.2) with the conditions

$$
v_{q}^{p(i)}\left(k_{i}\right)=\alpha_{p q}^{i} ; 2 \leq i \leq r, 1 \leq p, q \leq n
$$

where $\mathrm{v}_{\mathbf{q}}^{\mathrm{p}(\mathrm{i})}\left(\mathrm{k}_{\mathrm{i}}\right)$ is the $\mathrm{qth}$ component at $\mathrm{k}_{\mathrm{i}}$ for the pth backward solution. Substituting (2.7) into the adjoint identity (2.5) with $\mathrm{k}_{0}=\mathrm{k}_{1}$, we obtain

$$
\sum_{q=1}^{n} \alpha_{p q}^{i} u_{q}\left(k_{i}\right)-\sum_{q=1}^{n} v_{q}^{p(i)}\left(k_{1}\right) u_{q}\left(k_{1}\right)=\sum_{l=k_{1}+1}^{k_{i}} \sum_{q=1}^{n} v_{q}^{p(i)}(l) b_{q}(l-1), 2 \leq i \leq r .
$$

Summing ( $\mathrm{r}-1)$ equations (2.8) and making use of (1.2), we get

$$
\begin{gathered}
\sum_{q=1}^{n}\left[\alpha_{p q}^{i}+\sum_{i=2}^{r} v_{q}^{p(i)}\left(k_{1}\right)\right] u_{q}\left(k_{1}\right)=l_{p}-\sum_{i=2}^{r} \sum_{l=k_{1}+1}^{k_{i}} \sum_{q=1}^{n} v_{q}^{p(i)}(l) b_{q}(l-1), \\
1 \leq p \leq n .
\end{gathered}
$$

If the matrix $\left[\alpha_{p q}^{i}+\sum_{i=2}^{r} v_{q}^{p(i)}\left(k_{1}\right)\right]$ is nonsingular, then the system (2.9) provides the unknowns $\mathrm{u}_{\mathrm{q}}\left(\mathrm{k}_{1}\right), 1 \leq \mathrm{q} \leq \mathrm{n}$. The solution of the problem (1.1) and (1.2) is obtained by computing the solution of $(1.1)$ with these values of $u_{q}\left(k_{1}\right), 1 \leq q \leq n$. However, to evaluate the summation term in (2.9) we need to store the solutions of (2.1). This can be avoided at the cost of solving another $(\mathrm{r}-1)$ system. For this, we denote

$$
w_{p(i)}(k)=-\sum_{l=k+1}^{k_{i}} \sum_{q=1}^{n} v_{q}^{p(i)}(l) b_{q}(l-1) ; 1 \leq p \leq n, 2 \leq i \leq r
$$

which is equivalent to solving 


$$
\begin{gathered}
w_{p(i)}(k)=-\sum_{q=1}^{n} v_{q}^{p(i)}(k+1) b_{q}(k)+w_{p(i)}(k+1) \\
w_{p(i)}\left(k_{i}\right)=0 ; 1 \leq p \leq n, 2 \leq \mathrm{i} \leq \mathrm{r} .
\end{gathered}
$$

Thus, at the point $\mathrm{k}_{\mathrm{i}}, 2 \leq \mathrm{i} \leq \mathrm{r}$, we solve a system of order $2 \mathrm{n}$ given by (2.1) and (2.10) subject to the conditions (2.7) and (2.11).

With this adjustment system (2.9) takes the form

$$
\sum_{q=1}^{n}\left[\alpha_{p q}^{1}+\sum_{i=2}^{n} v_{q}^{p(i)}\left(k_{1}\right)\right] u_{q}\left(k_{1}\right)=l_{p}+\sum_{i=2}^{r} w_{p(i)}\left(k_{1}\right), 1 \leq p \leq n .
$$

This method of constructing the solution of (1.1) and (1.2) is called the backwardforward process and requires $(r-1) n$ backward solutions of the adjoint system (2.1) satisfying (2.7), ( $\mathrm{r}-1)$ backward solutions of (2.10) satisfying (2.11), and 1 forward solution of (1.1) with the obtained values of $\mathrm{u}_{\mathrm{q}}\left(\mathrm{k}_{1}\right), 1 \leq \mathrm{q} \leq \mathrm{n}$, from the system (2.12), i.e., a total of $(r-1)(n+1)+1$ solutions of $n$th order systems. In particular, if $r=2$ then we need $(n+2)$ solutions. Similar to the backward-forward process we have the forwardbackward process. For this we solve (2.1) forward once for each $\mathrm{u}_{\mathrm{q}}\left(\mathrm{k}_{\mathrm{i}}\right), 1 \leq \mathrm{i} \leq \mathrm{r}-1$, appearing in (1.2) with the conditions

$$
v_{-q}^{p(i)}\left(k_{i}\right)=\alpha_{p q}^{1} ; 1 \leq i \leq r-1,1 \leq p, q \leq n
$$

where $v_{-q}^{p(i)}\left(k_{i}\right)$ is the qth component at $k_{i}$ for the pth forward solution.

Substituting (2.13) into the adjoint identity (2.6) with $\mathrm{k}_{0}=\mathrm{k}_{\mathrm{r}}$, we obtain

$$
\begin{array}{r}
\sum_{q=1}^{n} \alpha_{p q}^{i} u_{q}\left(k_{i}\right)-\sum_{q=1}^{n} v_{q}^{p(i)}\left(k_{r}\right) u_{q}\left(k_{r}\right)=-\sum_{l=k_{i}+1}^{k_{r}} \sum_{q=1}^{n} v_{q}^{p(i)}(l) b_{q}(l-1), \\
1 \leq i \leq r-1 .
\end{array}
$$

Summing ( $\mathrm{r}-1)$ equations (2.14) and making use of (1.2), we get

$$
\begin{gathered}
\sum_{q=1}^{n}\left[\alpha_{p q}^{r}+\sum_{i=1}^{r-1} v_{-q}^{p(i)}\left(k_{r}\right)\right] u_{q}\left(k_{r}\right)=l_{p}+\sum_{i=1}^{r-1} \sum_{l=k_{i}+1}^{k_{r}} \sum_{q=1}^{n} v_{-q}^{p(i)}(l) b_{q}(l-1), \\
1 \leq p \leq n .
\end{gathered}
$$


We introduce

$$
w_{-p(i)}(k)=\sum_{\imath=k_{i}+1}^{k} \sum_{q=1}^{n} v_{-q}^{p(i)}(l) b_{q}(l-1) ; 1 \leq p \leq n, 1 \leq i \leq r-1,
$$

which is equivalent to solving

$$
\begin{gathered}
w_{-p(i)}(k)=-\sum_{q=1}^{n} v_{q}^{p(i)}(k+1) b_{q}(k)+w_{-p(i)}(k+1) \\
w_{-p(i)}\left(k_{i}\right)=0 ; 1 \leq p \leq n, 1 \leq i \leq r-1 .
\end{gathered}
$$

Thus, the system (2.15) is the same as

$$
\sum_{q=1}^{n}\left[\alpha_{p q}^{r}+\sum_{i=1}^{r-1} v_{-q}^{p(i)}\left(k_{r}\right)\right] u_{q}\left(k_{r}\right)=l_{p}+\sum_{i=1}^{r-1} w_{-p(i)}\left(k_{r}\right), 1 \leq p \leq n .
$$

The solution of the problem (1.1) and (1.2) is obtained by solving backward the system (1.1) with the obtained values of $\mathrm{u}_{\mathrm{q}}\left(\mathrm{k}_{\mathrm{r}}\right), 1 \leq \mathrm{q} \leq \mathrm{n}$ from the system (2.18).

Next we shall consider the system (1.1) together with the implicit separated conditions (1.3). We compute $\left(n-\beta_{1}\right)$ solutions of (2.1) backward with the conditions

$$
\mathrm{v}_{\mathrm{q}}^{\mathrm{i}\left(\mathrm{s}_{\mathrm{i}}\right)}\left(\mathrm{k}_{\mathrm{i}}\right)=\alpha_{\mathrm{i}\left(\mathrm{s}_{\mathrm{i}}\right), \mathrm{q}} ; 2 \leq \mathrm{i} \leq \mathrm{r}, 1 \leq \mathrm{s}_{\mathrm{i}} \leq \beta_{\mathrm{i}}, 1 \leq \mathrm{q} \leq \mathrm{n},
$$

where $\mathrm{v}_{\mathbf{q}}^{\mathrm{i}\left(\mathrm{s}_{\mathrm{i}}\right)}\left(\mathrm{k}_{\mathrm{i}}\right)$ is the $\mathrm{qth}$ component at $\mathrm{k}_{\mathrm{i}}$ for the $\mathrm{s}_{\mathrm{i}}$ th backward solution.

Substituting (2.19) into (2.5) with $\mathrm{k}_{0}=\mathrm{k}_{1}$ and using (1.3), we obtain

$$
\begin{gathered}
\sum_{q=1}^{n} v_{q}^{i\left(s_{i}\right)}\left(k_{1}\right) u_{q}\left(k_{1}\right)=l_{i, i}\left(s_{i}\right)-\sum_{l=k_{1}+1}^{k_{i}} \sum_{q=1}^{n} v_{q}^{i\left(s_{i}\right)}(l) b_{q}(l-1) ; \\
2 \leq i \leq r, 1 \leq s_{i} \leq \beta_{i} .
\end{gathered}
$$

We introduce

$$
w_{i\left(s_{i}\right)}(k)=-\sum_{l=k+1}^{k_{i}} \sum_{q=1}^{n} v_{q}^{i\left(s_{i}\right)}(l) b_{q}(l-1) ; 2 \leq i \leq r, 1 \leq s_{i} \leq \beta_{i}
$$


which is equivalent to solving

$$
\begin{gathered}
w_{i}\left(s_{i}\right)(k)=-\sum_{q=1}^{n} v_{q}^{i\left(s_{i}\right)}(k+1) b_{q}(k)+w_{i}\left(s_{i}\right)(k+1) \\
w_{i}\left(s_{i}\right)\left(k_{i}\right)=0 ; \quad 2 \leq i \leq r, 1 \leq s_{i} \leq \beta_{i} .
\end{gathered}
$$

Thus, the system (2.20) can be written as

$$
\sum_{q=1}^{n} v_{q}^{i\left(s_{i}\right)}\left(k_{1}\right) u_{q}\left(k_{1}\right)=i_{i, i}\left(s_{i}\right)+w_{i}\left(s_{i}\right)\left(k_{1}\right) ; 2 \leq i \leq r, 1 \leq s_{i} \leq \beta_{i} .
$$

System (2.23) together with (1.3) for $\mathrm{i}=1$, i.e.,

$$
\sum_{q=1}^{n} \alpha_{1\left(s_{1}\right), q} u_{q}\left(k_{1}\right)=l_{1,1\left(s_{1}\right)}, 1 \leq s_{i} \leq \beta_{i},
$$

forms a system of $n$ equations in $n$ unknowns $u_{q}\left(k_{1}\right), 1 \leq q \leq n$. The solution of (1.1) and (1.3) is obtained by solving forward the system (1.1) with these values of $\mathrm{u}_{\mathrm{q}}\left(\mathrm{k}_{1}\right)$, $1 \leq \mathrm{q} \leq \mathrm{n}$.

In practice we couple the adjoint system (2.1) with the equation (2.21) and solve this system of $(n+1)$ equations from the point $k_{i}, 2 \leq i \leq r$ to $k_{1}$ with the conditions (2.19) and (2.22).

Similarly, in the forward-backward process for (1.1) and (1.3), the unknowns $\mathrm{u}_{\mathrm{q}}\left(\mathrm{k}_{\mathrm{r}}\right), 1 \leq \mathrm{q} \leq \mathrm{n}$ are computed from the system

$$
\begin{gathered}
\sum_{q=1}^{n} v_{q}^{i\left(s_{i}\right)}\left(k_{r}\right) u_{q}\left(k_{r}\right)=l_{i, i}\left(s_{i}\right)+w_{-i}\left(s_{i}\right) \\
\left(k_{r}\right) ; 1 \leq i \leq r-1,1 \leq s_{i} \leq \beta_{i}, \\
\left.\sum_{q=1}^{n} \alpha_{r(s}\right), q u_{q}\left(k_{r}\right)=l_{r, r}\left(s_{r}\right), 1 \leq s_{r} \leq \beta_{r},
\end{gathered}
$$

where $v_{-q}^{i\left(s_{i}\right)}(k)$ is the qth component of the $s_{i}$ th forward solution from the point $k_{i}$ of the adjoint system (2.1) satisfying

$$
\mathrm{v}_{-\mathrm{q}}^{\mathrm{i}\left(\mathrm{s}_{\mathrm{i}}\right)}\left(\mathrm{k}_{\mathrm{i}}\right)=\alpha_{\mathrm{i}\left(\mathrm{s}_{\mathrm{i}}\right), \mathrm{q}} ; 1 \leq \mathrm{i} \leq \mathrm{r}-1,1 \leq \mathrm{s}_{\mathrm{i}} \leq \beta_{\mathrm{i}}, 1 \leq \mathrm{q} \leq \mathrm{n}
$$

and $w_{-i\left(s_{i}\right)}(k)$ is the forward solution of the initial value problem

$$
\begin{gathered}
w_{-i\left(s_{i}\right)}(k)=-\sum_{q=1}^{n} v_{-q}^{i\left(s_{i}\right)}(k+1) b_{q}(k)+w_{-i\left(s_{i}\right)}(k+1) \\
w_{-i\left(s_{i}\right)}\left(k_{i}\right)=0 ; 1 \leq i \leq r-1,1 \leq s_{i} \leq \beta_{i} .
\end{gathered}
$$


The solution of (1.1) and (1.3) is obtained by solving backward the system (1.1) with the obtained values of $u_{q}\left(k_{r}\right), 1 \leq q<r$.

\section{NUMERICAL EXAMPLES}

We shall construct an appproximate solution of the continuous boundary value problem

$$
\begin{gathered}
y^{\prime \prime}=f(t) y+g(t) \\
y(\alpha)=A, y(\beta)=B
\end{gathered}
$$

by employing the discrete variable method due to Nomerov. Let $h=\frac{\beta-\alpha}{K+1}, t_{k}=\alpha+k h$, $k \in N(0, K+1), f_{k}=f\left(t_{k}\right), g_{k}=g\left(t_{k}\right)$, and $u(k)$ be the approximation to the true solution of $y(t)$ at $t_{k}$, satisfies the second order difference equation,

$$
\begin{aligned}
\left(-1+\frac{1}{12} h^{2} f_{k-1}\right) u(k-1)+ & \left(2+\frac{10}{12} h^{2} f_{k}\right) u(k)+\left(-1+\frac{1}{12} h^{2} f_{k+1}\right) u(k+1) \\
= & -\frac{1}{12} h^{2}\left(g_{k-1}+10 g_{k}+g_{k+1}\right), k \in N(1, K)
\end{aligned}
$$

together with the boundary conditions

$$
\mathrm{u}(0)=\mathrm{A}, \mathrm{u}(\mathrm{K}+1)=\mathrm{B} \text {. }
$$

Theorem 3.1. (see [12])The discrete boundary value problem (3.2) and (3.3) has a unique solution provided

(a) $\mathrm{f}(\mathrm{t}) \geq 0$ on $[\alpha, \beta]$ and $\frac{1}{12} \mathrm{~h}^{2} \mathrm{f}_{\mathrm{k}}<1, \mathrm{k} \in \mathrm{N}(0, \mathrm{~K}+1)$; or

(b) $\frac{1}{12} h^{2} \frac{10+2 \cos \frac{\pi}{\mathrm{K}+1}}{4 \sin ^{2} \frac{\pi}{2 \mathrm{~K}+1}} \quad \max _{\alpha \leq \mathrm{t} \leq \beta}|\mathrm{f}(\mathrm{t})| \leq 1$.

If $\frac{1}{12} h^{2} \underset{\alpha \leq t \leq \beta}{\operatorname{maxf}(t)<1}$, then in system form the problem (3.2) and (3.3) can be written as

$$
\begin{gathered}
u_{1}(k+1)=u_{2}(k) \\
u_{2}(k+1)=-\frac{c_{0}(k)}{c_{2}(k)} u_{1}(k)+\frac{c_{1}(k)}{c_{2}(k)} u_{2}(k)+d(k), k \in N(0, K-1) \\
u_{1}(0)=A, u_{2}(K)=B
\end{gathered}
$$


where $c_{0}(k)=1-\frac{1}{12} h^{2} f_{k}, c_{1}(k)=2+\frac{10}{12} h^{2} f_{k+1}, c_{2}(k)=1-\frac{1}{12} h^{2} f_{k+2}$ and

$$
\mathrm{d}(\mathrm{k})=\frac{1}{c_{2}(\mathrm{k})} \times \frac{1}{12} \mathrm{~h}^{2}\left[\mathrm{~g}_{\mathrm{k}}+10 \mathrm{~g}_{\mathrm{k}+1}+\mathrm{g}_{\mathrm{k}+2}\right] \text {. }
$$

Applying the backward-forward process for the boundary value problem (3.4) and (3.5), we note that $(2.1),(2.21),(2.19)$ and $(2.22)$ reduce to

$$
\begin{aligned}
& v_{1}^{2}(k)=-\frac{c_{0}(k)}{c_{2}(k)} v_{2}^{2}(k+1) \\
& v_{2}^{2}(k)=v_{1}^{2}(k+1)+\frac{c_{1}(k)}{c_{2}(k)} v_{2}^{2}(k+1) \\
& w_{2}(k)=-v_{2}^{2}(k+1) d(k)+w_{2}(k+1) \\
& v_{1}^{2}(K)=0, v_{2}^{2}(K)=1, w_{2}(K)=0
\end{aligned}
$$

Further, the system (2.23) and (2.24) takes the form

which easily determines

$$
\begin{gathered}
v_{1}^{2}(0) u_{1}(0)+v_{2}^{2}(0) u_{2}(0)=B+w_{2}(0) \\
u_{1}(0)=A
\end{gathered}
$$

$$
u_{1}(0)=A, u_{2}(0)=\frac{B+w_{2}(0)-v_{1}^{2}(0) A}{v_{2}^{2}(0)} .
$$

The solution of (3.4) and (3.5) is obtained by recursing forward the system (3.4) with the initial values (3.8).

Similarly, applying the forward-backward process we find that (2.1), (2.28), (2.27) and (2.29) reduce to

$$
\begin{gathered}
\mathrm{v}_{-1}^{1}(\mathrm{k}+1)=\mathrm{v}_{-2}^{1}(\mathrm{k})+\frac{\mathrm{c}_{1}(\mathrm{k})}{\mathrm{c}_{0}(\mathrm{k})} \mathrm{v}_{-1}^{1}(\mathrm{k}) \\
\mathrm{v}_{-2}^{1}(\mathrm{k}+1)=-\frac{\mathrm{c}_{2}(\mathrm{k})}{\mathrm{c}_{0}(\mathrm{k})} \mathrm{v}_{-1}^{1}(\mathrm{k}) \\
\mathrm{w}_{-1}(\mathrm{k}+1)=\mathrm{w}_{-1}(\mathrm{k})+\mathrm{v}_{-2}^{1}(\mathrm{k}+1) \mathrm{d}(\mathrm{k}) \\
\mathrm{v}_{-1}^{1}(0)=1, \mathrm{v}_{-2}^{1}(0)=0, \mathrm{w}_{-1}(0) .
\end{gathered}
$$

Further, the system (2.25) and (2.26) becomes

$$
\begin{gathered}
v_{-1}^{1}(K) u_{1}(K)+v_{-2}^{1}(K) u_{2}(K)=A+w_{-1}(K) \\
u_{2}(K)=B
\end{gathered}
$$


which gives

$$
u_{1}(K)=\frac{A+w_{-1}(K)-v_{-2}^{1}(K) B}{v_{1}^{1}(K)}, u_{2}(K)=B .
$$

The solution of (3.4) and (3.5) is obtained by recursing backward the system (3.4) with the final values (3.11).

Example 3.1. For the discrete analogue (3.4) and (3.5) of the boundary value problem

$$
y^{\prime \prime}=\frac{2}{t^{2}} y(t)-\frac{1}{t} ; y(2)=0, y(3)=0,
$$

both the methods discussed in this section work equally well. The errors obtained, as calculated from the exact solution $y(t)=\frac{1}{36}\left(19 t-5 t^{2}-\frac{36}{t}\right)$ and approximate solution $u_{1}(k)$ with $\mathrm{h}=\frac{1}{256}$, are presented in Table 1 .

Table 1

\begin{tabular}{|c|c|c|}
\hline$t$ & $\begin{array}{c}\text { Backward-Forward } \\
\text { Method }\end{array}$ & $\begin{array}{c}\text { Forward-Backward } \\
\text { Method }\end{array}$ \\
\hline 2.000 & $0.00000000 \mathrm{D} 00$ & $0.64884418 \mathrm{D}-14$ \\
\hline 2.125 & $0.10546078 \mathrm{D}-12$ & $0.10817389 \mathrm{D}-12$ \\
\hline 2.250 & $0.15874801 \mathrm{D}-12$ & $0.15646512 \mathrm{D}-12$ \\
\hline 2.375 & $0.17716384 \mathrm{D}-12$ & $0.16960044 \mathrm{D}-12$ \\
\hline 2.500 & $0.16946167 \mathrm{D}-12$ & $0.15705492 \mathrm{D}-12$ \\
\hline 2.625 & $0.14502982 \mathrm{D}-12$ & $0.12977119 \mathrm{D}-12$ \\
\hline 2.750 & $0.10855900 \mathrm{D}-12$ & $0.93355879 \mathrm{D}-13$ \\
\hline 2.875 & $0.65239480 \mathrm{D}-12$ & $0.49092674 \mathrm{D}-13$ \\
\hline 3.000 & $0.16924973 \mathrm{D}-13$ & $0.00000000 \mathrm{D}-00$ \\
\hline
\end{tabular}

Example 3.2. For the discrete analogue (3.4) and (3.5) of the boundary value problem

$$
y^{\prime \prime}=400 y ; y(0)=1, y(5)=e^{-100},
$$

we apply both the methods. The errors obtained, as calculated from the exact solution $y(t)=e^{-20 t}$ and approximate solution $u_{1}(k)$ with $h=\frac{5}{1024}$, are presented in Table 2. 


\section{Table 2}

\begin{tabular}{|c|c|c|}
\hline $\mathbf{t}$ & $\begin{array}{c}\text { Backward-Forward } \\
\text { Method }\end{array}$ & $\begin{array}{c}\text { Forward-Backward } \\
\text { Method }\end{array}$ \\
\hline 0.0000 & & $0.16875390 \mathrm{D}-13$ \\
\hline 0.3125 & & $0.22852524 \mathrm{D}-08$ \\
\hline 0.6250 & & $0.88231446 \mathrm{D}-11$ \\
\hline 0.9375 & & $0.25548999 \mathrm{D}-13$ \\
\hline 1.2500 & & $0.65761522 \mathrm{D}-16$ \\
\hline 1.5625 & & $0.15868691 \mathrm{D}-18$ \\
\hline 1.8750 & & $0.36760514 \mathrm{D}-21$ \\
\hline 2.1875 & & $0.82791852 \mathrm{D}-24$ \\
\hline 2.5000 & Fails & $0.18265803 \mathrm{D}-26$ \\
\hline 2.1825 & & $0.39668934 \mathrm{D}-29$ \\
\hline 3.1250 & & $0.85087791 \mathrm{D}-32$ \\
\hline 3.4375 & & $0.18068378 \mathrm{D}-34$ \\
\hline 3.7500 & & $0.38051077 \mathrm{D}-37$ \\
\hline 4.0625 & & $0.79577134 \mathrm{D}-40$ \\
\hline 4.3750 & & $0.16543683 \mathrm{D}-42$ \\
\hline 4.6875 & & $0.34217867 \mathrm{D}-45$ \\
\hline 5.0000 & & $0.00000000 \mathrm{D}-00$ \\
\hline & & \\
\hline & & \\
\hline & & \\
\hline & & \\
\hline
\end{tabular}

Example 3.3. The boundary value problem

$$
y^{\prime \prime}=\left(2 m+1+t^{2}\right) y ; y(0)=\beta, y(\infty)=0,
$$

where $m \geq 0$ and $\beta$ are known constants, is known as Holt's problem. This problem is a typical example wherein usual shooting methods fail [2,5,7,9-11]. Replacing the boundary condition $y(\infty)=0$ by $y(T)=0$ ( $T$ finite) Holt [8] used finite difference methods (however, for $\mathrm{m}=0, \beta=1, \mathrm{~T}=12 ; \mathrm{m}=1, \beta=\pi^{-1 / 2}, \mathrm{~T}=8 ; \mathrm{m}=2, \beta=\frac{1}{4}, \mathrm{~T}=8$, the results are unsatisfactory $[8,11])$, whereas Osborne [9] used a multiple shooting method and Roberts and Shipman [10] used a multi-point approach. In [2] we have formulated a new shooting method which gives accurate solutions of (3.12) for several different values of $m$ and $\beta$ up to $T=18$. (This value of $T$ has been chosen in view of restricted computer capabilities.) For the same and several other values of $m$ and $\beta$ accurate solutions of (3.12) up to $T=18$ have also been obtained in [5]. Here the error estimates in the solution of (3.12) when approximating $\mathrm{y}(\infty)=0$ by an appropriate boundary condition at $\mathrm{T}$ are also available. For the discrete analogue (3.4) and (3.5) of (3.12) (replacing $\mathrm{y}(\infty)=0$ by $\mathrm{y}(18)=0$ ) with $\mathrm{m}=$ $0, \beta=1$ and $h=\frac{1}{60}$, we apply both the methods of this section. The numerical solution $\mathrm{u}_{1}(\mathrm{k})$ is shown in Table 3. 


\section{Table 3}

\begin{tabular}{|c|c|c|}
\hline$t$ & $\begin{array}{c}\text { Backward-Forward } \\
\text { Method }\end{array}$ & $\begin{array}{c}\text { Forward-Backward } \\
\text { Method }\end{array}$ \\
\hline 0.0 & & $0.10000000 \mathrm{D}-01$ \\
\hline 1.0 & & $0.25934255 \mathrm{D}-00$ \\
\hline 2.0 & & $0.34564046 \mathrm{D}-01$ \\
\hline 3.0 & & $0.19885232 \mathrm{D}-02$ \\
\hline 4.0 & & $0.45958196 \mathrm{D}-04$ \\
\hline 5.0 & & $0.41255769 \mathrm{D}-06$ \\
\hline 6.0 & & $0.14129840 \mathrm{D}-08$ \\
\hline 7.0 & & $0.18272052 \mathrm{D}-11$ \\
\hline 8.0 & & $0.88629857 \mathrm{D}-15$ \\
\hline 9.0 & Fails & $0.16054990 \mathrm{D}-18$ \\
\hline 10.0 & & $0.10827935 \mathrm{D}-22$ \\
\hline 11.0 & & $0.27128207 \mathrm{D}-27$ \\
\hline 12.0 & & $0.25206584 \mathrm{D}-32$ \\
\hline 13.0 & & $0.86750117 \mathrm{D}-38$ \\
\hline 14.0 & & $0.11047255 \mathrm{D}-43$ \\
\hline 15.0 & & $0.52013857 \mathrm{D}-50$ \\
\hline 16.0 & & $0.90485908 \mathrm{D}-57$ \\
\hline 17.0 & & $0.58130757 \mathrm{D}-64$ \\
\hline 18.0 & & $0.00000000 \mathrm{D}-00$ \\
\hline & &
\end{tabular}

Example 3.4. For the discrete analogue (3.4) and (3.5) of the boundary value problem

$$
y^{\prime \prime}=(\sin 2 t) y+\cos 2 t ; y(-1)=y(1)=0,
$$

we apply both the methods. The numerical solution $\mathrm{u}_{1}(\mathrm{k})$ for $\mathrm{h}=\frac{1}{540}$ is shown in Table 4 . 
12 Journal of Applied Mathematics and Stochastic Analysis Volume 3, Number 1, 1990

\section{Table 4}

\begin{tabular}{|c|c|c|}
\hline $\mathbf{t}$ & $\begin{array}{c}\text { Backward-Forward } \\
\text { Method }\end{array}$ & $\begin{array}{c}\text { Forward-Backward } \\
\text { Method }\end{array}$ \\
\hline-1.0 & $0.00000000 \mathrm{D}-00$ & $0.22781405 \mathrm{D}-13$ \\
\hline-0.9 & $-0.54219742 \mathrm{D}-01$ & $-0.54219742 \mathrm{D}-01$ \\
\hline-0.8 & $-0.11017210 \mathrm{D}-00$ & $-0.11017210 \mathrm{D}-00$ \\
\hline-0.7 & $-0.16531803 \mathrm{D}-00$ & $-0.16531803 D-00$ \\
\hline-0.6 & $-0.21715198 \mathrm{D}-00$ & $-0.21715198 \mathrm{D}-00$ \\
\hline-0.5 & $-0.26336748 \mathrm{D}-00$ & $-0.26336748 D-00$ \\
\hline-0.4 & $-0.30200211 \mathrm{D}-00$ & $-0.30200211 D-00$ \\
\hline-0.3 & $-0.33154697 \mathrm{D}-00$ & $-0.33154697 D-00$ \\
\hline-0.2 & $-0.35101159 \mathrm{D}-00$ & $-0.35101159 \mathrm{D}-00$ \\
\hline-0.1 & $-0.35994166 \mathrm{D}-00$ & $-0.35994166 \mathrm{D}-00$ \\
\hline 0.0 & $-0.35839390 \mathrm{D}-00$ & $-0.35839390 \mathrm{D}-00$ \\
\hline 0.1 & $-0.34687723 \mathrm{D}-00$ & $-0.34687723 \mathrm{D}-00$ \\
\hline 0.2 & $-0.32627260 \mathrm{D}-00$ & $-0.32627260 \mathrm{D}-00$ \\
\hline 0.3 & $-0.29774424 \mathrm{D}-00$ & $-0.29774424 \mathrm{D}-00$ \\
\hline 0.4 & $-0.26265376 \mathrm{D}-00$ & $-0.26265376 \mathrm{D}-00$ \\
\hline 0.5 & $-0.22248554 \mathrm{D}-00$ & $-0.22248554 \mathrm{D}-00$ \\
\hline 0.6 & $-0.17878818 D-00$ & $-0.17878818 D-00$ \\
\hline 0.7 & $-0.13313322 \mathrm{D}-00$ & $-0.13313322 \mathrm{D}-00$ \\
\hline 0.8 & $-0.87088932 \mathrm{D}-01$ & $-0.87088932 \mathrm{D}-01$ \\
\hline 0.9 & $-0.42204687 \mathrm{D}-01$ & $-0.42204687 \mathrm{D}-01$ \\
\hline 1.0 & $-0.58914799 \mathrm{D}-12$ & $0.00000000 \mathrm{D}-00$ \\
\hline
\end{tabular}




\section{REFERENCES}

[1] R.P. Agarwal, Initial-value Methods for Discrete Boundary Value Problems, J. Math. Anal. Appl. 100 (1984), 513-529.

[2] R.P. Agarwal and R.C. Gupta,On the Solution of Holt's Problem, BIT 24 (1984), 342-346.

[3] R.P. Agarwal, Computational Methods for Discrete Boundary Value Problems, Appl. Math. Comp. 18 (1986), 15-41.

[4] E. Angel and R. Kalaba, A One-sweep Numerical Method for Vector-matrix Difference Equations with Two-point Boundary Conditions, J. Optimization Theory and Appl. 6 (1970), 345-355.

[5] K. Balla and M. Vicsek, On the Reduction of Holt's Problem to a Finite Interval, Numer. Math. 51 (1987), 291-302.

[6] C.W. Clenshaw, A Note on the Summation of Chebyshev Series, MTAC, 9 (1955), 118-120.

[7] R.C. Gupta and R.P. Agarwal, A New Shooting Method for Multi-point Discrete Boundary Value Problems, J. Math. Anal. Appl. 112 (1985), 210-220.

[8] J.F. Holt, Numerical Solution of Nonlinear Two-point Boundary-value Problems by Finite-difference Methods, Commun. ACM 7 (1964), 366-373.

[9] M.R. Osborne, On Shooting Methods for Boundary Value Problems, J. Math. Anal. Appl. 27 (1969), 417-433.

[10] S.M. Roberts and J.S. Shipman, Multipoint Solution of Two-point Boundary-value Problems, J. Optimization Theory and Appl. 7 (1971), 301-318.

[11] S.M. Roberts and J.S. Shipman, Two-point Boundary Value Problems: Shooting Methods, Elsevier, New York (1972).

[12] R.A. Usmani and R.P. Agarwal, On the Numerical Solution of Two Point Discrete Boundary Value Problems, Appl. Math. Comp. 25 (1988), 247-264. 


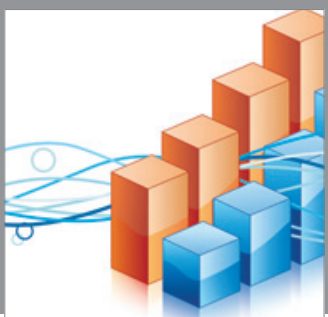

Advances in

Operations Research

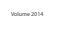

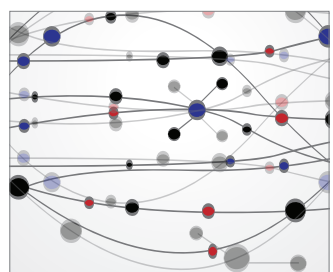

\section{The Scientific} World Journal
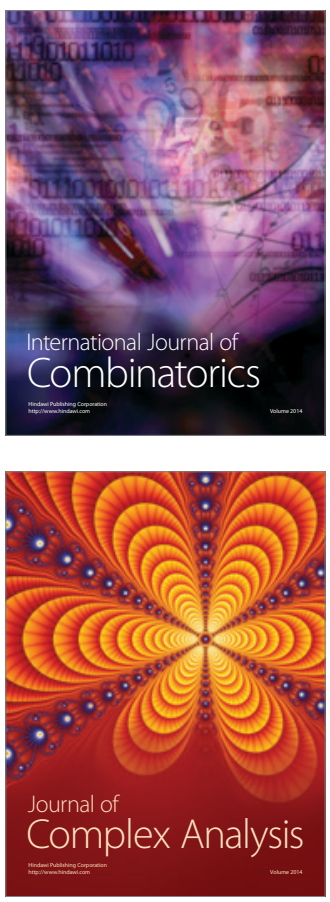

International Journal of

Mathematics and

Mathematical

Sciences
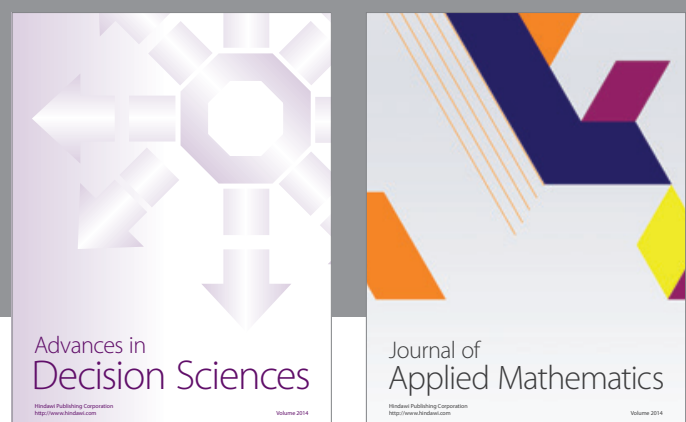

Journal of

Applied Mathematics
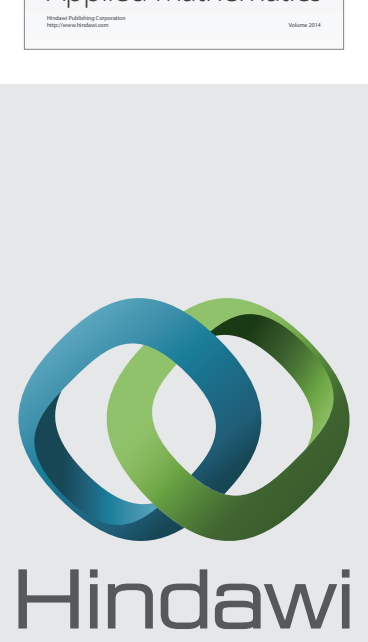

Submit your manuscripts at http://www.hindawi.com
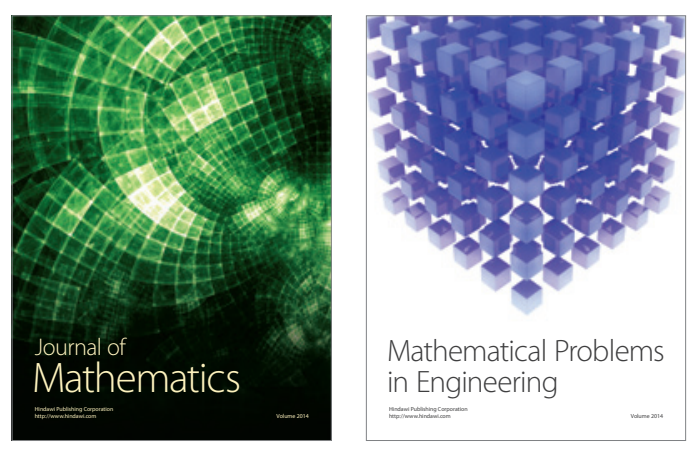

Mathematical Problems in Engineering
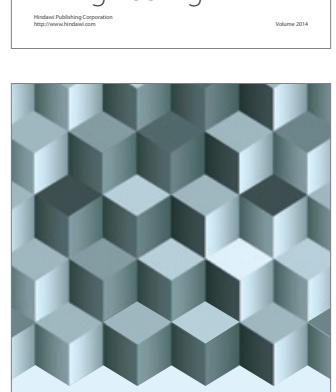

Journal of

Function Spaces
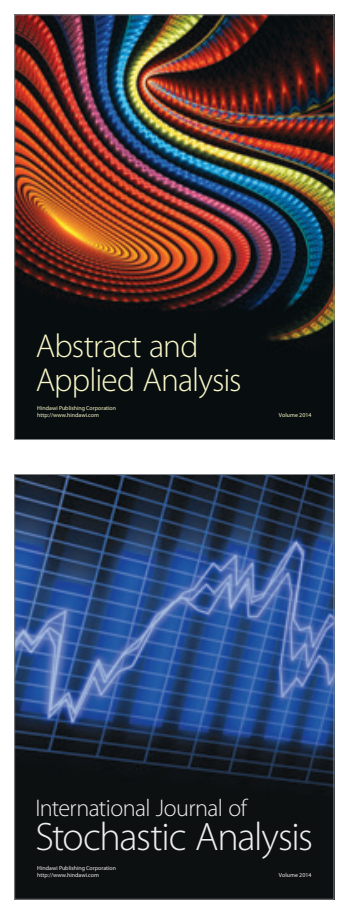

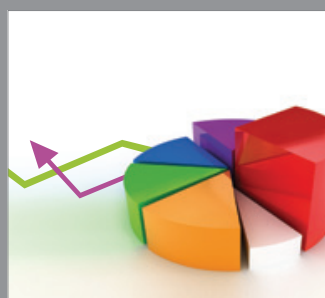

ournal of

Probability and Statistics

Promensencen
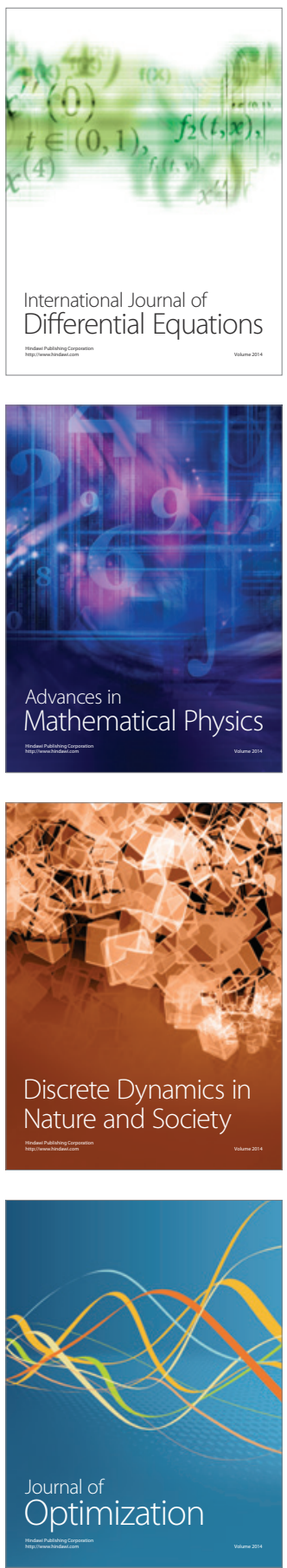